\title{
Neonatal Pneumomediastinum and the Spinnaker-Sail Sign
}
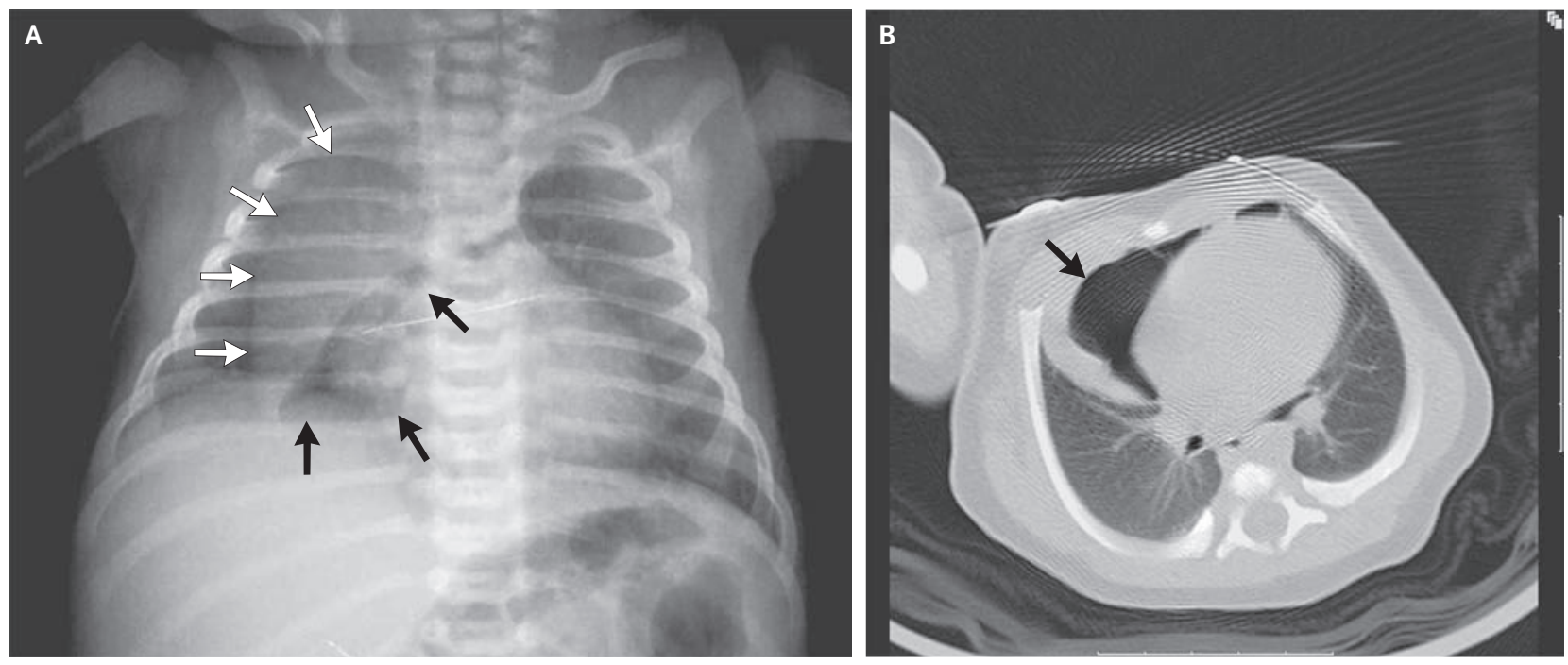

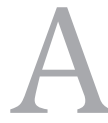

MALE INFANT WAS BORN AT 40 WEEKS OF GESTATION BY VACUUMassisted vaginal delivery. Mild respiratory distress with expiratory grunting and subcostal retraction was noted 1 hour after birth. Arterial oxygen saturation remained at more than $95 \%$ without the administration of supplemental oxygen. Chest radiography performed 6 hours after birth (Panel A) showed the spinnakersail sign, consisting of a large, wedge-shaped opacity extending from the right hemidiaphragm to the superior mediastinum (white arrows), representing thymic tissue displaced from its usual location by a collection of gas under pressure (black arrows). Axial computed tomography of the chest revealed air trapped between the pericardial sac and the thymus, confirming a diagnosis of anterior pneumomediastinum (Panel B, arrow). Named for its visual resemblance to the headsail of a boat, the spinnaker-sail sign occurs with a spontaneous anterior pneumomediastinum and usually resolves without specific treatment. After being observed for clinical and radiographic improvement for 3 weeks, the infant was discharged home in good condition.

Copyright ( 2010 Massachusetts Medical Society.
Jorge Correia-Pinto, M.D., Ph.D. Tiago Henriques-Coelho, M.D., Ph.D.

Hospital de Sao Joao

Porto, Portugal

jcp@ecsaude.uminho.pt 